\title{
A EXTENSÃo UNIVERSITÁRIA COMO LÓCUS DE FORMAÇÃO DO ESTAGIÁRIO/TERAPEUTA EM FONOAUDIOLOGIA PARA O ATENDIMENTO DE SUJEITOS COM TRANSTORNO DO ESPECTRO AUTISTA (TEA)
}

\author{
LA EXTENSIÓN UNIVERSITARIA COMO LUGAR DE FORMACIÓN DE \\ ESTUDIANTES/TERAPEUTA DEL HABLA Y LENGUAJE PARA ATENCIÓN DE \\ PACIENTES CON TRASTORNO DEL ESPECTRO AUTISTA (TEA)
}

\section{UNIVERSITY EXTENSION AS AN ACADEMIC FORMATION PLACE FOR THE TRAINEE/THERAPIST IN PHONOAUDIOOGY FOR THE ATTENDANCE TO AUTISTIC SPECTRUM DISORDER (ASD) PATIENTS}

\author{
Lais Oliva DONIDA ${ }^{1}$ \\ Dayane Stephanie POTGURSKI ${ }^{2}$ \\ Vitor Martins GUESSER ${ }^{3}$ \\ Maria Eduarda Martins de OLIVEIRA ${ }^{4}$
}

RESUMO: O objetivo deste trabalho é relatar a experiência de estagiários/terapeutas em um projeto de extensão universitária de atendimento fonoaudiológico para sujeitos com diagnóstico de TEA. Os dados foram gerados a partir da resposta de um questionário semiestruturado em que participaram dois acadêmicos. Dentre as principais reflexões dos acadêmicos participantes, se pode observar que a frustração com relação à prática terapêutica para pessoas sem oralidade e diagnóstico de TEA foi um relato recorrente. A percepção do distanciamento entre teoria e prática e a angústia do atendimento clínico para um Outro que não responde às expectativas do estagiário/terapeuta também foi ressaltada pelos acadêmicos. Assim, se conclui que a extensão, enquanto lócus de formação, deve levar em conta a subjetividade do estagiário/terapeuta, para que ele possa ser amparado em outras esferas para além daquela do conhecimento teóricoprático, mas também como lugar de escuta essencial para sua trajetória profissional futura.

PALAVRAS-CHAVE: Autismo. Extensão. Fonoaudiologia. Formação.

RESUMEN: El objetivo de este artículo es informar la experiencia de los aprendices/terapeutas del habla y language en un proyecto de extensión universitaria de logopedia para sujetos diagnosticados con TEA. Los datos se generaron a partir de la respuesta de un cuestionario semiestructurado en el que participaron dos académicos. Entre las principales reflexiones de los académicos participantes, se puede observar que la frustración con respecto a la práctica terapéutica para personas sin oralidad y diagnóstico de TEA fue un informe recurrente. Los académicos también destacaron la percepción de la

1 Universidade Federal de Santa Catarina (UFSC), Florianópolis - SC - Brasil. Fonoaudióloga, mestre e doutoranda em Linguística. ORCID: https://orcid.org/0000-0003-3508-7030. E-mail: lais.donida@ gmail.com.

${ }^{2}$ Universidade Federal de Santa Catarina (UFSC), Florianópolis - SC - Brasil. Graduanda em Fonoaudiologia. ORCID: https://orcid.org/0000-0001-8646-6271. E-mail: dayanepotgurski@gmail.com.

${ }^{3}$ Universidade Federal de Santa Catarina (UFSC), Florianópolis - SC - Brasil. Graduado em Fonoaudiologia. ORCID: https://orcid.org/0000-0003-1594-1711. E-mail: vitorguesser_@hotmail.com.

${ }^{4}$ Universidade Federal de Santa Catarina (UFSC), Florianópolis - SC - Brasil. Graduanda em Fonoaudiologia. ORCID: https://orcid.org/0000-0002-3156-3207. E-mail: duudaa94@gmail.com. 
distancia entre la teoría y la práctica y la ansiedad de la atención clínica para un Otro que no cumple con las expectativas del internolterapeuta. Por lo tanto, se puede concluir que la extensión, como lugar de formación, debe tener en cuenta la subjetividad del aprendiz/terapeuta, para que pueda ser apoyado en otras esferas además de la del conocimiento teórico y práctico, pero también como un lugar de escucha esencial para el estudiante. su futuro camino professional.

PALABRAS CLAVE: Autismo. Extensión. Terapia del habla. Formación.

ABSTRACT: The objective of this paper is to report the experience of the Trainees/Therapists in a university's extension project of Phonoaudiology for subjects diagnosed with ASD. Data was generated from the response of a semi-structured questionnaire in which two academics participated. Among the main reflections of the participating academics, it can be observed that the frustration regarding the therapeutic practice for people without orality and diagnosed with ASD was a recurrent report. The perception of the distance between theory and practice and the anxiety of clinical care for an 'Other' that does not meet the expectations of the trainee/therapist was also highlighted by the academics. Thus, it can be concluded that extension, as a locus of formation, must take into account the subjectivity of the trainee/therapist, so that he/she can be supported in other spheres besides that of theoretical and practical knowledge, but also as a place of essential listening for the student's future career path.

KEYWORDS: Autism. Extension. Phonoaudiology. Formation.

\section{Introdução}

Na América Latina, o papel que a Universidade assume resulta em um compromisso social que abarca uma posição para além das perspectivas originalmente formuladas sob uma lógica capitalista. Assim, o desenvolvimento regional sustentável, a diminuição das desigualdades sociais e políticas de inclusão e permanência na Educação Superior são objetivos intrínsecos ao sistema de ensino (KOEHNTOPP; HERDT, 2018).

Desse modo, a formação dos estudantes nas Universidades do país segue tendências voltadas ao entrelaçamento entre pesquisa, ensino e extensão como forma de interligar os conhecimentos produzidos na academia com o retorno voltado ao desenvolvimento social, garantindo também a qualidade da formação dos futuros profissionais e a transformação social (SOUSA, 2013). Dessa forma, segundo Manchur, Suriani e Cunha:

A extensão universitária é um dos caminhos para desenvolver uma formação acadêmica completa, que integra teoria e prática numa comunicação com a sociedade e possibilita uma troca de saberes entre ambos. Através dessa ação acontece a socialização e construção de novos conhecimentos (2013, p. 335). 
A extensão universitária emerge, por conseguinte, como um elo entre a instituição e a sociedade no momento em que os processos de ensino e aprendizagem se efetivam. Nesse sentido, ela é "um jeito de ser, uma maneira de dialogar e uma possibilidade de aprender" (SÍVERES, 2013, p. 20). Isso significa dizer que a instituição de Educação Superior, em sua ação (trans)formadora social, acolhe as diversidades, as pluralidades e a torna-se "uni" ao permitir que o dialogismo entre as esferas da sociedade e do conhecimento transbordem-se. É, portanto, através do dialogismo inscrito entre os processos de ensinar e aprender e entre os sujeitos, que a extensão universitária se posiciona como lócus (trans)formador. Ou seja,

pautar o processo educativo como uma ação e reflexão é fazer da educação um empreendimento que acolhe as necessidades e as demandas da sociedade e, por meio do projeto formativo e profissionalizante, contribuir com o desenvolvimento social. Além dessa diretriz institucional pública, é oportuno propor que se comuniquem, também, as suas mediações aprendentes (SÍVERES, 2013, p. 26).

Apesar de muitos estudos referirem-se à extensão universitária como possibilidade de obter experiência na formação de estudantes de cursos de licenciaturas (MANCHUR; SURIANI; CUNHA, 2013; MENEGON, et al., 2015), muito se discute acerca dos proveitos oferecidos também em extensões de cursos de bacharel. Em Santa Catarina, por exemplo,

O caráter extensionista é estabelecido por meio de projetos de intervenção social, a partir de elementos característicos de uma determinada comunidade, e que podem desenvolver o potencial de promover inovações sociais e, até mesmo, de base tecnológica (FRANCISCO, 2018, p. 16).

Assim, a Universidade Federal de Santa Catarina (UFSC) tem destaque, uma vez que preza pela tríade de ensino, pesquisa e extensão, o que a coloca em evidência não somente a âmbito regional e nacional, mas também internacionalmente. Com isso, a UFSC permite o ingresso e a permanência de estudantes através da oferta de bolsas e trabalho voluntário, assim como possibilita que o ensino e os serviços sejam oferecidos com qualidade para a comunidade (BORTOLINI; OTANI; MELO, 2018).

\section{A extensão universitária como lócus de formação na Fonoaudiologia}

A formação universitária em cursos da saúde também segue os movimentos políticoeconômicos e educacionais que estão em curso no país. Assim, além de promover a inclusão e a permanência de estudantes na instituição de ensino, a extensão permite a diversificação de metodologias de ensino e aprendizagem (PORTO, 2017). Segundo Goés et al., (2018, p. 431), 
os projetos de extensão, "[n]a área da saúde, assumem particular importância por servir de espaço para propiciar ações de humanização". Contudo, vê-se que as discussões acerca do impacto da participação em projetos de extensão na formação de estudantes de Fonoaudiologia ainda são incipientes e, que estas ainda se pautam em práticas assistencialistas. Assim,

a integração da Fonoaudiologia na Extensão Universitária permite uma construção de conhecimento em conjunto com a comunidade, o que possibilita a percepção dos fatores socioculturais nos distúrbios da comunicação humana. A atuação fonoaudiológica na extensão se dá por meio da elaboração e efetivação de ações que apontem soluções para questionamentos da população, bem como a adoção de medidas preventivas cabíveis, prestando educação em saúde de qualidade à população (GOÉS, et al., 2018, p. 431432).

Em outro estudo, realizado por Faustino (2009), observa-se que a extensão universitária realizada em um curso de Fonoaudiologia não está relacionada somente a ações que retornam ou partem da comunidade, de uma ou de outra forma, conforme pontuado por Goés et al. (2018). Faustino (2009) ressalta que a extensão é necessária para a formação dos acadêmicos, uma vez que permite superar dificuldades em aplicar o conhecimento teórico na prática clínica, principalmente em casos de atendimentos para pessoas que possuem diagnóstico de Transtorno do Espectro Autista (TEA).

A partir disso, observa-se que há uma lacuna de pesquisas que consideram a extensão como parte da formação do sujeito enquanto relação dialógica, principalmente, em cursos de Fonoaudiologia. Ou seja, a extensão é "um processo mediador de construção do conhecimento e uma atividade que aponta para a finalidade do percurso da aprendizagem” (SÍVERES, 2013, p. 20).

É nesse ínterim que este artigo emerge, a partir reflexões que se desdobraram a partir das experiências de estudantes em atividades desenvolvidas no projeto de extensão intitulado “Atendimento Clínico Fonoaudiológico a Crianças e Adultos", realizado na Clínica Escola de Fonoaudiologia da UFSC. Esta extensão universitária tem como objetivo proporcionar aprofundamento teórico-prático de estudantes do curso de Fonoaudiologia e docentes/fonoaudiólogos em situações concretas de atendimento clínico e pesquisa na área da linguagem, visando um aprimoramento de ensino e aprendizagem.

Além disso, a proposta da presente extensão é que a abordagem teórico-prática se ancore em uma concepção interacionista e dialógica da linguagem (BAKHTIN, 2011; VIGOTSKI, 2010; BERBERIAN; SANTANA, 2012; SIGNOR, 2012). O acompanhamento fonoaudiológico, nessa perspectiva, se constitui como um trabalho dialógico. O trabalho com/para e na linguagem é realizado na interação entre diversos sujeitos que aí se constituem e 
são constituídos: paciente e família; família e clínica; família e terapeuta; paciente e terapeuta; terapeuta e professor orientador; e também entre o grupo como um todo (constituído por estudantes, docentes de Fonoaudiologia e outros profissionais de outras áreas).

A partir do exposto, o objetivo deste trabalho é relatar a experiência de estagiários/terapeutas em um projeto de extensão universitária de atendimento fonoaudiológico para sujeitos com Transtorno do Espectro Autista (TEA).

\section{Contornos metodológicos}

Os dados foram gerados a partir dos relatos de dois acadêmicos, sendo um do sexto e um do oitavo semestre de graduação. Os relatos foram coletados a partir de um questionário online durante o período de março a junho de 2019.

O questionário continha as seguintes perguntas para reflexão: i) Como você se sente com relação ao setting terapêutico com seus pacientes com TEA? II) Você se sente preparado no quesito teórico-prático? III) O que você pode definir como primordial na sua formação para o atendimento de pessoas com TEA? IV) Qual o seu sentimento em relação às dificuldades dos seus pacientes? VII) Você acredita que a extensão está ajudando na sua formação? Se sim, de que forma?

A análise dos dados se deu a partir da Análise de Conteúdo de Bardin (2011), em que estudos em torno da temática foram mobilizados para o tratamento crítico dos relatos, sendo estes apresentados ao leitor ao longo da discussão tecida.

Inicialmente, apresenta-se ao leitor, uma análise de palavras realizada com o software Wordclouds, como forma de ressaltar os anseios mais pontuados pelos acadêmicos. Posteriormente, os relatos foram categorizados por três eixos principais, sendo eles:

I) A relação com o Outro: Este eixo envolve as temáticas em torno do sentimento com relação à própria prática clínica e também os anseios com relação à "resposta" do Outro, nesse caso, da criança sem oralidade e com diagnóstico de TEA;

II) Obstáculos na relação entre teoria e prática: Este eixo envolve os relatos em que os acadêmicos pontuam dificuldades em entrelaçar prática e teoria, assim como discussões acerca dos processos de aprendizagem;

III) A extensão como locus formador: Eixo em que os estagiários/terapeutas comentam acerca do papel da extensão em sua formação acadêmica e pessoal; 


\section{Resultados e discussões}

Para Vigotski (2010), a palavra permite com que o sujeito reflita acerca do processo ao qual se circunscreve. É a palavra, na mediação com o outro, que faz com que o aprendizado ocorra. A palavra escrita dos acadêmicos, portanto, assume o caráter de processo mediador do sentimento ao qual o desconhecido causa estranhamento, e, consequentemente, a reflexão e a ressignificação. Dessa forma,

Compreendendo, porém, que o diálogo é um elemento inerente à instituição educativa, é adequado destacar a importância de contribuir para com o sentido da pessoa e da história, pautar o processo educativo como uma ação e reflexão e promover possibilidades diferenciadas de experiências educativas (SÍVERES, 2013, p.25).

Se concebe aqui, portanto, que a extensão é o lugar de "escuta" para os acadêmicos que estão em sofrimento diante do "não-saber", do "desconhecido". Assim, a formação do estagiário/terapeuta em Fonoaudiologia perpassa a mediação da palavra do outro mais experiente: do colega, do docente, do profissional. Com isso, esperar-se-ia que os acadêmicos, ao apropriarem-se da teoria, a coloquem em prática durante os atendimentos e compreendam o sujeito com diagnóstico de TEA como aquele que se constitui pelo Outro, nesse caso o estagiário/terapeuta, mas este também se constitui nessa relação.

Conforme pode-se ver abaixo na Figura 1, há algumas palavras que são marcadas nos relatos dos acadêmicos, sendo elas: "TEA", "difícil”, "frustração", "atenção". Outras palavras ganham destaque secundário durante os relatos: "observações", "estratégias", "agitado", "medo", "interação", "alegria" e "prática". E essas palavras, signos, revelam marcas da interação com o Outro.

Figura 1 - Análise de palavras realizada com o software Wordclouds

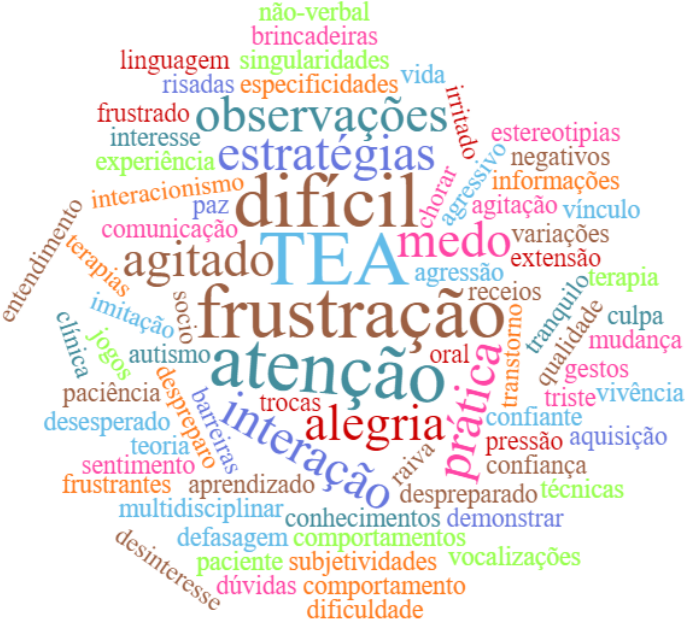

Fonte: Elaborado pelos autores. 
É com esse arcabouço teórico que se concebe a extensão também como um lugar de aprendizagem mediada (VIGOTSKI, 2010). Assim, os estudantes se encontram em uma zona de desenvolvimento proximal que, a partir da interação com o outro "mais experiente", mediada por signos (palavras, ações), conseguirá se apropriar dos conhecimentos e técnicas necessárias para o atendimento clínico fonoaudiológico. Nesse sentido, o desenvolvimento do acadêmico engloba diversas áreas de formação humana, inclusive o seu desenvolvimento enquanto ser social.

\section{I) A relação com o Outro}

Aparentemente, no inventário da prática clínica fonoaudiológica que os acadêmicos se encontram, há um julgamento que lhes é iminente, um julgamento que os coloca no lugar do "saber" enquanto eles se encontram no lugar de "aprendizes". Esse lugar social ao qual se circunscrevem lhes causa muitas angústias, de modo que a extensão é o lócus ideal para fortalecer capacidades, habilidades e entrecruzar a práxis terapêutica. Dessa forma, os estagiários/terapeutas relatam que durante esse "encontro com o Outro", com o "desconhecido", em verdade, há o encontro com a "frustração", conforme se vê nos relatos abaixo:

Estagiário/terapeuta 1: Inicialmente, me senti frustrado pelo fato de eu preparar diversas atividades para os 45 minutos de terapia e o paciente não ter interesse em nenhuma delas. Além do fato de a criança não interagir comigo em nenhum momento, tendo comportamento agitado e solicitando através de gestos para sair da sala. [...] Bom, frustração era o principal sentimento nas primeiras sessões. Após entender o comportamento da criança que possui TEA, passei a deixar de lado todo esse sentimento e me concentrar em fazer com que o paciente tivesse a intenção de interagir. No início foi dificil, porém procuro sempre ter paciência e me manter ciente de que o paciente não faz isso de modo proposital, e que ele apenas não saber como interagir/brincar com alguém. [...] No início eu ficava desesperado por achar que era uma maneira dele de demonstrar que estava irritado ou triste, fazendo com que eu pensasse que as estereotipias eram uma demonstração apenas de sentimentos negativos. Após observações do paciente, vi que em muitos momentos as estereotipias eram uma forma de demonstrar sentimento de alegria. Sendo assim, quando a criança faz alguma estereotipia (como por exemplo girar e balançar as mãos), eu imito ele e, ao mesmo tempo, cantarolando "gira, gira". Ao fazer isso, o paciente mostra-se feliz através de risadas e vocalizações.

Estagiário/terapeuta 2: Inicialmente senti muita dificuldade e frustração, pois além de ser o meu primeiro contato com a prática clínica, com essa vivência de terapeuta/paciente, era um paciente não-verbal com uma certa preferência por terapeutas do sexo masculino e com um tempo de atenção muito reduzido. Planejar atividades para as sessões eram frustrantes pois 
muitas vezes o paciente não mostrava interesse no que era proposto. [...] Em relação ao sentimento, acredito que a frustração e medo. A frustração ainda encontra-se presente, não na mesma proporção que antes, pois agora estou aprendendo a lidar com isso, a entender que não é proposital quando o paciente não demonstra interesse na atividade e nem mesmo é nossa culpa isso acontecer. Quanto ao medo, é medo no sentido de ter dúvidas se está fazendo diferença na vida dele, se os minutos de terapia vão resultar em alguma mudança, se os pais realmente acreditam no atendimento e que vale a pena se deslocar até o local onde acontece a terapia.

A partir do exposto, pode-se perceber que a extensão se configura como um lócus que acolhe a "frustração" dos acadêmicos diante do atendimento de crianças sem oralidade e com diagnóstico de TEA. Contudo, como diria Arantes (2005, p. 153), “[d]e lado, ficou a reflexão sobre o sentido da presença dos processos dialógicos em falas patológicas". Assim, percebe-se que os acadêmicos, ao centrarem-se apenas na "não-resposta do Outro", acabam se frustrando por não compreenderem ainda aspectos relacionados ao conhecimento própria da área da linguagem.

Sendo assim, o trabalho de construção do conhecimento deve ser realizado de maneira coletiva, permitindo ser este um lugar do "não saber", comum a todos. Além disso, é necessário que o mediador da coletividade esteja atento para aspectos da ordem do individual, uma vez que:

é preciso conhecer como cada indivíduo responde às dificuldades, aos problemas e aos fracassos, visto que são esses processos motivacionais que correspondem a expectativas, atribuições e sentimentos que irão auxiliar a pessoa a superar as dificuldades e a sustentar a motivação (CARVALHO; SÍVERES, 2013, p. 40).

Assim, é somente a partir do desenrolar dos acontecimentos, durante a experiência compartilhada ao longo dos atendimentos clínicos, que os acadêmicos passam a compreender o que está acontecendo entre esse Outro - neste caso, o sujeito sem oralidade e com diagnóstico de TEA - e sua prática clínica e conhecimento teórico. Isso se revela em alguns trechos dos excertos, como quando o Terapeuta 1 enuncia:

No início eu ficava desesperado por achar que era uma maneira dele de demonstrar que estava irritado ou triste, fazendo com que eu pensasse que as estereotipias eram uma demonstração apenas de sentimentos negativos. Após observações do paciente, vi que em muitos momentos as estereotipias eram uma forma de demonstrar sentimento de alegria.

E no relato do Terapeuta 2:

A frustração ainda encontra-se presente, não na mesma proporção que antes, pois agora estou aprendendo a lidar com isso, a entender que não é proposital 
quando o paciente não demonstra interesse na atividade e nem mesmo é nossa culpa isso acontecer.

Nesse sentido, conforme enuncia Arantes:

A natureza do que se tem a avaliar/diagnosticar - a linguagem - na pluralidade dos efeitos de seu funcionamento, é responsável pela complexidade envolvida neste processo e é exigência para o clínico "elaborar um dizer sobre a linguagem" (2005, p. 155, grifos da autora).

Às vezes, a prática e a teoria são caminhos de aprendizagem paralelas que se entrecruzam somente em determinado momento. E, nesse entrecruzar, há a transformação da zona de desenvolvimento proximal, representada por um conhecimento que ainda necessita da mediação, para um aprendizado real (VIGOTSKI, 2010). Assim, vê-se pelos relatos que os estagiários/terapeutas apresentam dificuldades com as práticas terapêuticas de linguagem, uma vez que, para eles, a teoria ainda não se materializou na prática. Isto porque o conhecimento teórico se mostra muito distante do sentimento real que os estudantes apresentam diante da "não interação com seus pacientes". Assim, a extensão, enquanto processo de formação, deve abarcar a subjetividade dos envolvidos, para que ela possa ser compreendida para além de um processo clínico "mecânico", ou seja, um processo de resiliência e amadurecimento dos próprios estudantes/estagiários.

\section{II) Obstáculos na relação entre teoria e prática}

A extensão se configura também como o lugar da chamada "aprendizagem conceitual", conforme aponta Costa, Baiotto e Garces (2013). Ou seja, para a formação profissional, é necessário que os estudantes dominem certas técnicas ou aprofundem conceitos, conhecimentos. Nos relatos abaixo, os estagiário/terapeutas em Fonoaudiologia mencionam que a teoria e a prática lhes parece muito distante: embora os textos acadêmicos e as aulas teóricas proporcionadas pelo curso apontam para determinadas alterações linguísticocognitivas em pessoas com TEA, o fato é que a experiência, o encontro com esse Outro relatado pela literatura, só se efetiva na prática. É aí, então, que surgem as incertezas, as dúvidas.

Estagiário/terapeuta 1: Não. Na teoria tudo parece fácil. Nós aprendemos técnicas e estratégias para melhorar a interação e aquisição da linguagem oral do paciente que possui TEA, por exemplo. Porém, na prática, há barreiras como a atenção diminuída, o não saber brincar e agitação. Ou seja, não aprendemos a lidar com os diversos tipos de comportamentos. [...] Basicamente todos [os comportamentos], devido à falta de teoria. [...] os conteúdos são passados rapidamente e sem aulas práticas, como por exemplo observações em alguma instituição, sendo difícil relacionar teoria com 
prática, fazendo com que eu me sinta despreparado quando entro em contato com alguém que possui algum transtorno de comportamento para atendê-lo. [...] Com certeza mais aulas teóricas sobre transtornos psiquiátricos, e também prática. Nós temos teoria sobre autismo, por exemplo, e de repente já estamos em um estágio com paciente que possui TEA, muito agitado, agressivo, sem nem mesmo saber o que fazer quando o paciente nos agride de alguma forma ou começa a chorar. Além de nos formamos para trabalhar com a comunicação de uma pessoa, devemos aprender a agir frente aos comportamentos dos pacientes.

Estagiário/terapeuta 2: Bom, teoricamente eu diria que sim, pois tomamos conhecimentos sobre o que é, quais são, que estratégias utilizar e como interagir. Porém, quando chega na prática, vemos que não estamos preparados, que não é bem assim, que assim como cada transtorno de comportamento, cada sujeito possui suas especificidades e singularidades. [...] Acredito que não tem como especificar apenas um, pois cada transtorno possui variações de manifestações e cada sujeito tem suas subjetividades. [...] Seria interessante uma mesma carga horária para teoria e prática, pois essa defasagem na prática nos faz chegar muito "cru" na hora do atendimento, criando assim alguns sentimentos negativos em relação a nós e ao paciente. Acredito que se fossem proporcionadas algumas observações, palestras ou até mesmo participações em grupos de pais, nos sentiríamos um pouco mais confiantes na prática clínica. [...] Muitas vezes, por não conseguir identificar se o sentimento que desencadeou tal estereotipia [no paciente], se foi raiva, frustração elou alegria, acabo tentando desviar daquela possível situação problema, tento chamar atenção dele para um outro objeto elou uma outra atividade. Pouquíssimas vezes eu acabei imitando ele.

Os relatos revelam que a terapia a ser realizada com sujeitos com TEA e sem oralidade promovem desconforto e uma tensão entre os estagiários, que se desanimam frente às tentativas frustrantes de interação. Diante do choro, das estereotipias e da ausência da comunicação, do medo de ser mordido e/ou atacado pelo paciente, temos os terapeutas que apresentam sentimentos de conflitos. É possível também observar que fantasias e realidade se intercruzam com as inseguranças e o medo do "novo" e do afastamento que se tem da teoria para a prática, além da necessidade de resiliência perante as situações de frustração.

Assim, a extensão proporciona o caráter educativo que se encontra nessa "ação" (o movimentar-se em direção ao desconhecido, buscando o conhecimento) e, ao mesmo tempo, a "reflexão" (o lugar do "não saber" e do "ser aprendiz" para a (trans)formação social), em consonância com o que pontua Síveres (2013). Desta forma, “[a] relação do conhecimento nos projetos de extensão se dará na intersubjetividade dos sujeitos sociais, ao buscarem compreender o (des)conhecido" (COSTA; BAIOTTO; GARCES, 2013, p. 66). 


\section{III) A extensão como lócus formador:}

A extensão se configura como um lócus de mediação do aprendizado dos acadêmicos que, ao mesmo tempo em que os coloca diante da experiência do "erro", faz com que o conhecimento seja repassado por outros profissionais "mais experientes". Pesquisadores como Gonzatti, Dullius e Quartieri (2013) também afirmam que o valor da formação universitária só se efetiva quando se é capaz de retornar à diversos contextos da sociedade indivíduos mais críticos e autônomos. É nesse ínterim que emerge a extensão, apontada nos relatos dos estagiários/terapeutas em Fonoaudiologia como um lócus de "experiências":

Estagiário/terapeuta 1: Sim, pois quando comecei a participar da extensão, iniciei os atendimento com um paciente que possuía diagnóstico de TEA antes mesmo de se iniciarem os estágios obrigatórios do curso, sendo que nestes não haveria garantia de que eu atenderia algum paciente com TEA. E, adicionalmente, a extensão me deixou mais tranquilo e confiante para iniciar o atendimento nos estágios obrigatórios, já que a pressão psicológica é muito maior. Além disso, na extensão contamos com uma equipe multidisciplinar, onde há maior trocas de informações e garantia de um atendimento mais qualificado para o paciente, bem como a experiência de lidar com outros profissionais da saúde.

Estagiário/terapeuta 2: A extensão me proporcionou experiências as quais os estágios ainda não tinham proporcionado, o contato com a prática clínica, a qual resultou na diminuição dos medos e receios existentes relacionados com o primeiro contato com o outro. Além do ganho de conhecimento sobre uma outra perspectiva, o sócio interacionismo, que nos faz pensar num sujeito como um todo e não de modo individualista, pensando apenas na sua dificuldade.

Assim como apontado por estudos de Costa, Baiotto e Garces (2013), a extensão universitária proporciona uma preparação para os estágios curriculares obrigatórios nos cursos, o mesmo sendo relatado pelos dois estagiários/terapeutas participantes desta pesquisa.

Além disso, a extensão pode ser compreendida como um lugar em que a interação em grupo permite novas formas de atividades sociais (VIGOTSKI, 2010). Por estarem na chamada zona de desenvolvimento proximal (VIGOTSKI, 2010), os estagiários/terapeutas necessitam da troca de experiências promovida pelos profissionais e docentes, assim como com os colegas. Os participantes também mencionam que a formação extensionista realizada de forma trans/interdisciplinar corroborou de forma positiva, conforme o relato do Terapeuta 1: “[...] $a$ experiência de lidar com outros profissionais da saúde". Conforme aponta Costa, Baiotto e Garces:

Em projetos de extensão, a aprendizagem ocorre em grupos em que os estudantes pesquisados relataram que aprenderam a trabalhar em equipes, 
valorizando o trabalho do outro, e isso os possibilitou saber se expressar, aprender que existe hora de ouvir e de falar, discutir com profissionais de diferentes áreas e também conviver com os seus pares (2013, p. 69).

A partir do exposto, revela-se ser necessário que as ações de extensão também tenham a possibilidade da atuação de diferentes profissionais, uma vez que o conhecimento é (trans)formado a partir das práticas sociais de interação - efetivadas também a partir da aprendizagem de conhecimentos conceituais na clínica. Embora a prática se efetive na clínica fonoaudiológica, a participação de profissionais de outras áreas da saúde - e também da educação - se mostrou essencial para que, tanto os estagiários/terapeutas em Fonoaudiologia se (trans)formassem enquanto sujeitos organizadores de atividade social humanizadora, quanto a interação com os sujeitos sem oralidade e com diagnóstico de TEA fossem compreendidas e mediadas.

\section{Considerações finais}

O presente artigo teve como objetivo apresentar ao leitor o relato de experiência de estagiários/terapeutas em um projeto de extensão universitária de atendimento fonoaudiológico para sujeitos com diagnóstico de Transtorno do Espectro Autista (TEA).

Dentre as principais reflexões dos acadêmicos participantes, se pode observar que a frustração com relação à prática terapêutica para pessoas sem oralidade e diagnóstico de TEA foi um relato recorrente. A percepção do distanciamento entre teoria e prática e a angústia do atendimento clínico para um Outro que não responde às expectativas do estagiário/terapeuta também foi ressaltada pelos acadêmicos.

Assim, a partir das reflexões empreendidas, pode-se compreender que a extensão universitária se configura como:

- Elo (trans)formador dos sujeitos, dos conhecimentos, dos processos de ensino e aprendizagem;

- Projeto inter/transdisciplinar que possibilita a transgressão da práxis entre as áreas do conhecimento humano na Universidade;

- Possibilidade de encontro e diversificação de metodologias de ensino e aprendizagem nos cursos da saúde - e, nesse caso, principalmente para cursos de Fonoaudiologia;

- Lócus para fortalecer capacidades e habilidades dos acadêmicos e entrecruzar teoria e prática no acompanhamento fonoaudiológico voltado a pessoas com TEA;

- Lugar de desenvolvimento de potencialidades e ressignificação do sentimento de frustração dos estagiários/terapeutas em Fonoaudiologia; 
Dessa maneira, a extensão universitária pode contribuir para a permanência e diminuir a evasão nos cursos de Fonoaudiologia, uma vez que os estagiários/terapeutas podem encontrar um "lugar" - fora e anterior aos estágios obrigatórios - que oportunize que suas angústias sejam acolhidas e (trans)formadas. É necessário também que a extensão seja explorada pelos cursos como necessária para a formação acadêmica e que os mediadores dos projetos estejam capacitados para reconhecer essa diversidade de (não)saberes, frustrações, expectativas e ressignificá-las.

É imprescindível, portanto, que as instituições de Educação Superior invistam na tríade de ensino, pesquisa e extensão de modo a oferecer um ensino que possa contribuir para a autonomia e o desenvolvimento dos futuros profissionais.

\section{REFERÊNCIAS}

ARANTES, Lúcia. Sobre os efeitos do interacionismo no diagnóstico de linguagem.

Cad.Est.Ling., Campinas, n. 47, v. 1 e v. 2, pp. 151-157, jan./dez. 2005. Disponível em: https://periodicos.sbu.unicamp.br/ojs/index.php/cel/article/view/8637279/5001. Acesso em 28 nov. 2019.

BAKHTIN, Mikhail. Estética da criação verbal. São Paulo: Martins Fontes, 2011.

BARDIN, Laurence. Análise de Conteúdo. São Paulo: Edições 70, 2011.

BERBERIAN, Ana Paula; SANTANA, Ana Paula (Orgs.). Fonoaudiologia em contextos grupais: referenciais teóricos e práticos. São Paulo: Plexus; 2012.

BORTOLINI, Maristela Helena Zimmer; OTANI, Nilo; MELO, Pedro Antônio de (Orgs.). A Educação superior em Santa Catarina. Editora UFSC, Florianópolis, 2018. 738 p. Disponível em: http://150.162.1.90:8080/pergamumweb/vinculos/000001/00000134.pdf. Acesso em: 26 nov. 2019.

CARVALHO, Fabíola Gomide Baquero; SÍVERES, Luiz. A dinâmica motivacional no processo de ensino e aprendizagem na extensão universitária. p. 37-70. In: SÍVERES, Luiz (Org.). A Extensão universitária como um princípio de aprendizagem. Brasília: Liber Livro, 2013. 272 p. Disponível em: https://unesdoc.unesco.org/ark:/48223/pf0000232083. Acesso em: 26 nov. 2019.

COSTA, Aline Aparecida Cezar; BAIOTTO, Cléia Rozani; GARCES, Solange Beatriz Billlig. Aprendizagem: O olhar da extensão. p 61-80. In: SÍVERES, Luiz (Org.). A Extensão universitária como um princípio de aprendizagem. Brasília: Liber Livro, 2013. 272 p. Disponível em: https://unesdoc.unesco.org/ark:/48223/pf0000232083. Acesso em: 26 nov. 2019.

FRANCISCO, Thiago Henrique Almino. Apresentação. p. 13-16. In: BORTOLINI, Maristela Helena Zimmer; OTANI, Nilo; MELO, Pedro Antônio de (Orgs.). A Educação superior em 
Santa Catarina. Editora UFSC, Florianópolis, 2018. 738 p. Disponível em: http://150.162.1.90:8080/pergamumweb/vinculos/000001/00000134.pdf. Acesso em 26 nov. 2019.

FACCI, Marilda Gonçalves Dias. A periodização do desenvolvimento psicológico individual na perspectiva de Leontiev, Elkonin e Vigotski. Cad. CEDES, Campinas, v. 24, n. 62, p. 6481, apr. 2004 . Disponível em:

http://www.scielo.br/scielo.php?script=sci_arttext\&pid=S0101-

$32622004000100005 \& \operatorname{lng}=\mathrm{en} \& \mathrm{nrm}=$ iso. Acesso em: 27 nov. 2019.

GÓES, Thales Roges Vanderlei de; et al. Extensão universitária: perfil do discente de Fonoaudiologia de uma universidade pública. Distúrbios da Comunicação, v. 30, n. 3, p. 429-439, set. 2018. Disponível em: https://revistas.pucsp.br/dic/article/view/35226/26626. Acesso em: 26 nov. 2019.

GONZATTI, Sonia Elisa Marchi; DULLIUS, Maria Madalena; QUARTIERI, Marli Teresinha. O potencial da extensão para a formação profissional. p: 223-244. In: SÍVERES, Luiz (Org.). A Extensão universitária como um princípio de aprendizagem. Brasília: Liber Livro, 2013. 272 p. Disponível em: https://unesdoc.unesco.org/ark:/48223/pf0000232083. Acesso em: 26 nov. 2019.

KOEHNTOPP, Paulo Ivo; HERDT, Sebastião Salésio. Prefácio. p. 7-9. In: BORTOLINI, Maristela Helena Zimmer; OTANI, Nilo; MELO, Pedro Antônio de (Orgs.). A Educação superior em Santa Catarina. Editora UFSC, Florianópolis, 2018. 738 p. Disponível em: http://150.162.1.90:8080/pergamumweb/vinculos/000001/00000134.pdf. Acesso em: 26 nov. 2019.

MANCHUR, Josiane; SURIANI, Ana Lucia Affonso; CUNHA, Márcia Cristina da. A contribuição de projetos de extensão na formação profissional de graduandos de licenciaturas. Revista conexão UEPG, Ponta Grossa, PR, v. 9 n. 2 p. 334-341, 2013. Disponível em: https://www.revistas2.uepg.br/index.php/conexao/article/view/5522. Acesso em 26 nov. 2019.

MENEGON, Rodrigues. et al. A importância dos projetos de extensão no processo de formação inicial de professores de educação física. 14ª Jornada do Núcleo de Ensino, UNESP-Marília. 2015. Disponível em:

https://www.marilia.unesp.br/Home/Eventos/2015/jornadadonucleo/a-importancia-dosprojetos-de-extensao.pdf. Acesso em: 26 nov. 2019.

MILLAN, Ana Elisa; POSTALLI, Lidia Maria Marson. Ensino de Habilidades Rudimentares de Leitura para Alunos com Autismo. Revista Brasileira de Educação Especial, Bauru, v. 25, n. 1, p. 133-154, 2019. Disponível em: http://dx.doi.org/10.1590/s141365382519000100009. Acesso em: 26 nov. 2019.

PORTO, Vanessa Fernandes de Almeida. A extensão universitária e a formação profissional em cursos de graduação em saúde. Orientadora: Josineide Francisco Sampaio. 2017. 70 f. Dissertação (Mestrado em Ensino na Saúde) - Faculdade de Medicina, Programa de Pós-Graduação em Ensino na Saúde, Universidade Federal de Alagoas, Maceió, 2017. Disponível em: http://www.repositorio.ufal.br/bitstream/riufal/1786/1/A\%20extens\%C3\%A3o\%20universit\% 
$\mathrm{C} 3 \% \mathrm{~A} 1$ ria $\% 20 \mathrm{e} \% 20 \mathrm{a} \% 20$ forma\%C3\%A7\% C3\%A3o\%20profissional\%20em $\% 20$ cursos\%20 de\%20gradua\%C3\%A7\%C3\%A3o\%20em\%20sa\%C3\%BAde.pdf. Acesso em 26 nov. 2019.

SOUSA, Sônia Margarida Gomes. Prefácio. p. 11-14. In: SÍVERES, Luiz (Org.). A Extensão universitária como um princípio de aprendizagem. Brasília: Liber Livro, 2013. 272 p. Disponível em: https://unesdoc.unesco.org/ark:/48223/pf0000232083. Acesso em: 26 nov. 2019.

SIGNOR, Rita. Terapia fonoaudiológica em grupo voltada à linguagem escrita: uma perspectiva dialógica. RBLA, Belo Horizonte, v. 12, n. 3, p. 585-605, 2012. Disponível em: http://www.scielo.br/pdf/rbla/v12n3/a08v12n3. Acesso em 29 nov. 2019.

VIGOTSKI, Lev Semionovich. Lev Semionovich Vygotsky. Ivan Ivic; Edgar Pereira Coelho (org.) Recife: Fundação Joaquim Nabuco, Editora Massangana, 2010. 140 p.

\section{Como referenciar este artigo}

DONIDA, Lais Oliva; POTGURSKI, Dayane Stephanie; GUESSER, Vitor Martins; OLIVEIRA, A extensão universitária como lócus de formação do estagiário/terapeuta em fonoaudiologia para o atendimento de sujeitos com transtorno do espectro autista (tea). Temas em Educ. e Saúde, Araraquara, v. 15, n. 2, p. 248-262, jul./dez. 2019. e-ISSN 2526-3471. DOI: https://doi.org/10.26673/tes.v15i2.13162

Submetido em: 15/03/2019

Revisões requeridas: 25/04/2019

Aprovado em: 30/06/2019

Publicado em: 30/07/2019 